\title{
Avaliação das propriedades reológicas do trigo armazenado
}

\author{
Rheological properties evaluation of stored wheat
}

\section{Aparecido Nivaldo MÓDENES ${ }^{1 *}$, Acir Martins da SILVA², Daniela Estelita Goes TRIGUEROS ${ }^{3}$}

\section{Resumo}

Neste trabalho foi realizada uma avaliação das propriedades reológicas de trigo armazenado no período de 5 meses, objetivando dar subsídios para que as aquisições ou o uso do trigo possam ser feitos na colheita ou se necessitam de um tempo de repouso, para evolução das propriedades reológicas. Foram realizadas análises com 4 variedades de trigo Coodetec CD 104, CD 112, CD 200133 e CD 200213 . O intervalo entre as análises foi de 30 dias, iniciando na colheita até 150 dias de armazenamento. Foram analisados a Alveografia (força geral do glúten, tenacidade e extensibilidade da massa), o Teor de Glúten (Glúten úmido e seco) e o Número de Queda. Os resultados obtidos mostraram que, no período, não houve evolução na força do glúten e no número de queda. Pequenas variações que ocorreram nas outras análises, como tenacidade e extensibilidade, não são significativas do ponto de vista da indústria moageira. Desta forma, os resultados obtidos mostram que não existe a necessidade de retardar a aquisição e o uso do trigo na colheita em relação às propriedades reológicas, reduzindo desta forma o tempo e o custo de armazenamento.

Palavras-chave: Triticum aestivum; propriedades reológicas; número de queda; alveografia.

\begin{abstract}
The objective of this work was to evaluate the rheological properties of 5 months of storage of wheat and investigate how the method of storage influences the use of wheat and its rheological properties. The assays were conducted with 4 variations of wheat: CoodeteC - CD 104, CD 112, CD 200133 and CD 200213. The time interval between the assays was 30 days and the storage time was up to 150 days after harvest. Alveogram parameters (general gluten force, tenacity, and extensibility of mass), the humid and dried gluten, and falling number were evaluated. The obtained results indicated that during the chosen storage period the gluten force and falling number did not change. The other assays showed small variations, for example on tenacity and extensibility, but this fact is not significant from the industrial point of view. Hence, the obtained results demonstrated that there is no need to delay the acquisition and the use of wheat upon harvest based on its rheological properties since this type of storage increases its cost.
\end{abstract}

Keywords: Triticum aestivum; rheological properties; falling number; alveogram.

\section{Introdução}

Do plantio ao consumo, o trigo passa por várias etapas, transformando-se e chegando à mesa do consumidor através de inúmeros produtos diferenciados. Segundo Informações Técnicas da Reunião da Comissão Centro-Sul Brasileira de Pesquisa de Trigo e de Triticale (CCSBPT, 2004), após a colheita, devem ser tomados alguns cuidados tais como: não misturar grãos de cultivares diferentes; não misturar grãos com índices de queda diferentes; controlar a umidade na recepção dos lotes; e não misturar lotes com teores de umidade diferentes. Durante a secagem, não utilizar temperatura superior a $60^{\circ} \mathrm{C}$, pois a queima resulta em "perda irreversível" da qualidade do produto. Além disso, deve-se controlar insetos e pragas no armazenamento e procurar órgão oficial para a classificação do produto.

Segundo Rossi e Neves (2004), a qualidade do trigo é um conceito relativo, pois os atributos considerados para essa análise não são os mesmos nos diferentes "elos da cadeia”. No caso do produtor rural, o trigo de qualidade superior é aquele que possui boas características agronômicas, como resistência a doenças e pragas, alto potencial produtivo e alto peso do hectolitro. Para os moinhos, a qualidade será medida pela uniformidade do tamanho e forma da matéria-prima, alto peso específico, alto rendimento em farinhas e baixos teores de cinza. Já o panificador, busca adquirir uma farinha de boa qualidade, com alta capacidade de absorção de água, boa tolerância ao amassamento e alta porcentagem de proteína. Desta forma, para que se possa garantir a qualidade geral exigida em todos os "elos da cadeia", devem ser considerados diversos atributos, balanceando-se a qualidade produtiva com as características desejadas pelos consumidores.

A qualidade de grãos e farinhas de cereais é determinada por uma variedade de características que assumem diferentes significados dependendo da designação de uso ou tipo de

Recebido para publicação em 4/10/2007

Aceito para publicação em 29/6/2009 (002907)

${ }^{1}$ Programa de Mestrado em Engenharia Química, Universidade Estadual do Oeste do Paraná - Unioeste, Toledo - PR, Brasil, E-mail: modenes@unioeste.br

2 Moinho Cotriguaçú, Palotina - PR, Brasil,E-mail: acir@cotriguacu.com.br

${ }^{3}$ Programa de Mestrado em Engenharia Química, Universidade Estadual do Oeste do Paraná - Unioeste, Toledo - PR, Brasil, E-mail: estelita_trigueros@yahoo.com.br

${ }^{*}$ A quem a correspondência deve ser enviada 
produto. Estas características podem ser divididas em físicas, químicas enzimáticas e reológicas (RASPER, 1991).

Os testes físico-químicos utilizados na análise da qualidade do trigo são: Peso do hectolitro, Peso de mil grãos, Dureza de grãos, Proteínas, Cinzas ou resíduo mineral fixo, Número de queda, Sedimentação de Zeleny, Microssedimentação com sulfato dodecil de sódio (MD-SDS).

Os testes reológicos utilizados na análise de qualidade do trigo pelo mercado são:

Número de queda (FN): Este método mede a intensidade de atividade da enzima $\alpha$-amilase no grão, sendo o resultado expresso em segundos. Altos valores indicam baixa atividade dessa enzima, enquanto baixos valores indicam alta atividade, situação que comumente resulta do processo de germinação da espiga. Em clima quente e úmido, durante a maturação do grão, a atividade de $\alpha$-amilase aumenta. Pães elaborados com farinha que possuem alta atividade enzimática (NQ $<200$ s) tendem a apresentar miolo escuro e pegajoso.

Teor de glúten (glúten seco e úmido): O glúten é constituído por uma massa viscoelástica tridimensional que proporciona as características físicas e reológicas de plasticidade, viscosidade e elasticidade importantes para a massa (WIESIR, 2007; COSTA et al., 2008). O teste de glúten fornece a medida quantitativa dessas proteínas. De acordo com Mandarino (1993), o coeficiente de hidratação do glúten, que pode ser determinado a partir da operação de secagem para se obter o glúten seco, corresponde à quantidade de água eliminada durante o processo de secagem na estufa. (O coeficiente de hidratação é dado pela diferença entre o peso do glúten úmido e o peso do glúten seco).

Alveografia: Este teste simula o comportamento da massa na fermentação. As características viscoelásticas da farinha de trigo podem ser avaliadas por diferentes parâmetros da alveografia. A energia de deformação da massa ou força de glúten (W) representa o trabalho de deformação da massa e indica a qualidade panificativa da farinha, este teste corresponde ao trabalho mecânico necessário para expandir a bolha até a ruptura, expressa em $10^{-4} \mathrm{~J}$. A expressão "força de uma farinha" normalmente é utilizada para designar a maior ou a menor capacidade de uma farinha de sofrer um tratamento mecânico ao ser misturada com água. Também é associada à maior ou à menor capacidade de absorção de água pelas proteínas formadoras de glúten, combinadas à capacidade de retenção do gás carbônico, resultando num bom produto final de panificação, ou seja, pão de bom volume, de textura interna sedosa e de granulometria aberta (GUTKOSKI; NETO, 2002). A tenacidade $(\mathrm{P})$ mede a sobrepressão máxima exercida na expansão da massa, expressa em $\mathrm{mm}$, e corresponde a uma medida da capacidade de absorção de água da farinha. A extensibilidade da massa (L) é usada para predizer o volume do pão, juntamente com o teor de proteína e representa a capacidade de extensão da massa, sem que ela se rompa. Um alto grau de extensibilidade está associado a um baixo rendimento de farinha. A relação tenacidade/extensibilidade (P/L) expressa o equilíbrio da massa. Para a fabricação de pães, o ideal são farinhas balanceadas com uma relação P/L entre 0,50 e 1,20, e para massas alimentícias secas, farinha tenaz $(\mathrm{P} / \mathrm{L}>1,21)$.

No Brasil, a Instrução Normativa $\mathrm{n}^{\circ} 7$ do Ministério da Agricultura, Pecuária e Abastecimento (BRASIL, 2001), classifica os cultivares de acordo com a alveografia e o número de queda em cinco classes, como apresentado na Tabela 1.

Nas indústrias moageiras, algumas dúvidas norteiam o fato de que as características reológicas do cereal podem evoluir no período de 5 a 6 meses. Desta forma, apresenta-se o problema: Se as características reológicas do trigo evoluem com o passar do tempo, as aquisições do cereal para fins de moagem devem ser retardadas? Nesse contexto, este trabalho tem por objetivo analisar amostras do grão para verificar a evolução das características reológicas do grão no período de cinco meses de armazenamento.

\section{Material e métodos}

A metodologia de estudo adotada foi uma pesquisa de caráter exploratório, a qual selecionou 4 cultivares de trigo (variedades Coodetec CD 104, CD 112, CD 200133 e CD 200213) cultivadas nos campos da COODETEC (Cooperativa Central Agropecuária de Desenvolvimento Tecnológico e Econômico) no município de Palotina-PR. Todos os cultivares apresentaram igualdade de condições, semeadas em períodos diferentes para coincidirem a maturação e a colheita. Receberam tratamento de sementes para controle de pragas e doenças. Os 4 cultivares foram colhidos no mesmo dia e foram levados ao moinho para primeira análise e armazenamento. Durante o experimento, todas as análises foram realizadas em triplicatas, obedecendo as normas estabelecidas pelo Ministério da Agricultura. O local onde foram analisadas as amostras foi o laboratório do Moinho Cotriguaçu, localizado no município de Palotina, Estado do Paraná. O referido laboratório é credenciado pelo Ministério da Agricultura desde 10 de setembro de 1997. Os testes reológicos realizados para análise de qualidade do trigo foram:

Número de queda (FN): determinado de acordo com o método 56-81B da AACC (1995) através do equipamento Falling Number, modelo 1500 Fungal (Perten Instruments, Suíça), utilizando sete gramas de farinha, corrigido para $14 \%$ de unidade.

Teor de glúten: determinado em aparelho Glutomatic pelos métodos 38-10 e 38-12 da AACC (1995), utilizando-se o aparelho Glutomatic (Peter Instruments North America Inc., Reno, USA). A porcentagem de glúten úmido foi obtida na base

Tabela 1. Classificação de trigo segundo a Instrução Normativa ${ }^{\circ} 7$, de 15 de agosto de 2001, do Ministério da Agricultura, Pecuária e Abastecimento (BRASIL, 2001).

\begin{tabular}{lcc}
\hline \multicolumn{1}{c}{ Classe } & $\begin{array}{c}\text { Alveografia W } \\
\left(10^{-4} \mathrm{~J}\right) \text { mínimo }\end{array}$ & $\begin{array}{c}\text { Número de queda } \\
(\text { segundos }) \text { mínimo }\end{array}$ \\
\hline Trigo brando & 50 & 200 \\
Trigo pão & 180 & 200 \\
Trigo melhorador & 300 & 250 \\
Trigo para outros usos & Qualquer & $<200$ \\
Trigo Durum & Não determinado & 250 \\
\hline
\end{tabular}


de $14 \%$ de umidade, calculando-se a relação entre o peso total do glúten úmido/g e 100\% de umidade da amostra.

Alveografia: As características viscoelásticas das amostras da farinha foram determinadas no alveógrafo Chopin, modelo NG (Villeneuve-la-Garenne Cedex, França), utilizando-se o método $\mathrm{n}^{\circ}$ 54-30 da AACC (1995) através da pesagem de $250 \mathrm{~g}$ de farinha e volume de 129,4 $\mathrm{mL}$ de água, corrigido na base de $14 \%$ de umidade. Os parâmetros obtidos nos alveogramas são: tenacidade, que mede a sobrepressão máxima exercida na expansão da massa $(\mathrm{mm})$; extensibilidade, que mede o comprimento da curva ( $\mathrm{mm}$ ) e energia de deformação da massa, que corresponde ao trabalho mecânico necessário para expandir a bolha até a ruptura, expressa em $10^{-4} \mathrm{~J}$.

\section{Resultados e discussão}

O primeiro teste reológico utilizado na análise de qualidade do trigo foi a Força geral de glúten, que representa o trabalho de deformação da massa e indica a qualidade panificativa da farinha. Analisando os resultados obtidos, apresentados na Figura 1, verifica-se que, durante o tempo de armazenamento não ocorreu variação significativa. As pequenas variações ocorridas estão dentro da margem de erro permissível da análise. Na Figura 1, nota-se que não há uma tendência de aumento ou de redução. Portanto, podemos afirmar que não houve variação da Força geral de glúten com o tempo.

Analisando-se os resultados obtidos para o glúten úmido e seco, apresentados nas Figuras 2 e 3, respectivamente, verifica-se que não há evolução do glúten úmido no período de 150 dias e também não ocorre nenhuma tendência clara de evolução no glúten seco. Portanto, podemos afirmar que não houve variação do teor de glúten com o tempo neste período.

Os resultados obtidos para os testes de tenacidade e extensibilidade são apresentados nas Figuras 4 e 5, respectivamente. Analisando-se os resultados apresentados na Figura 4, verifica-se que ocorreu um pequeno aumento da

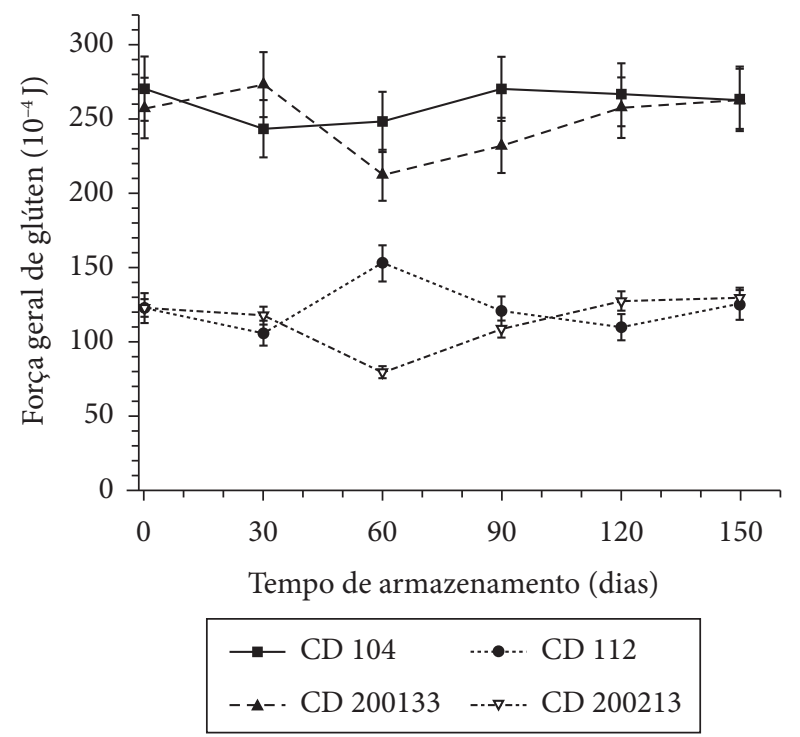

Figura 1. Força geral de glúten em função do tempo de armazenamento. tenacidade durante os trinta primeiros dias de armazenamento, seguido de uma queda e um novo aumento. Apesar do erro permissível esperado na análise, podemos verificar uma leve tendência de aumento na tenacidade com o tempo de armazenamento. Com relação à extensibilidade, como apresentado na Figura 5, com exceção do CD200213 que permaneceu praticamente constante, pode-se esperar uma pequena redução da extensibilidade com o tempo de armazenamento.

$\mathrm{Na}$ análise do Número de queda apresentada na Figura 6, verifica-se um pequeno aumento no índice de queda para o CD 104 e CD 112, mas, devido ao erro permissível do método, esta diferença pode ser desconsiderada. Assim, podemos afirmar

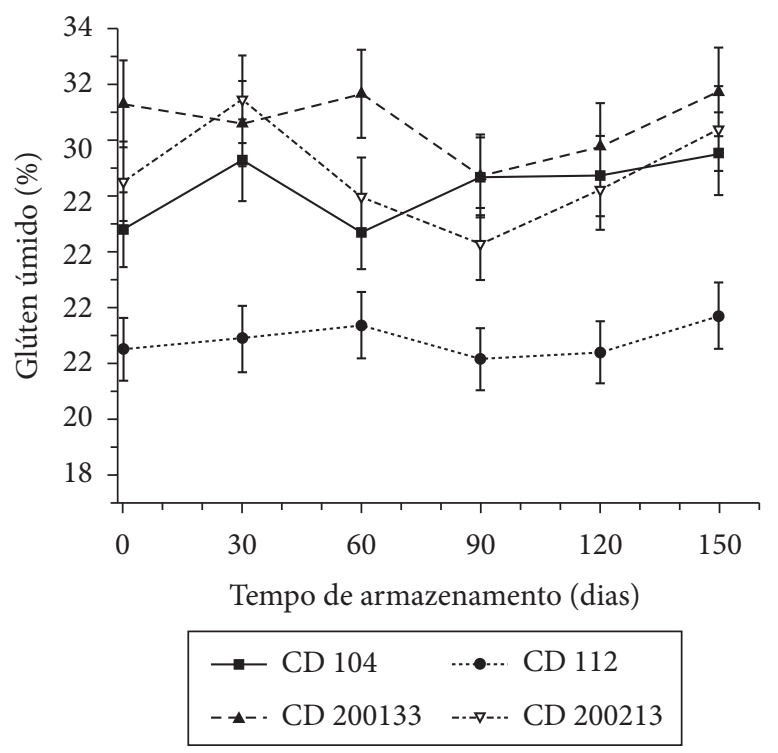

Figura 2. Glúten úmido em função do tempo de armazenamento.

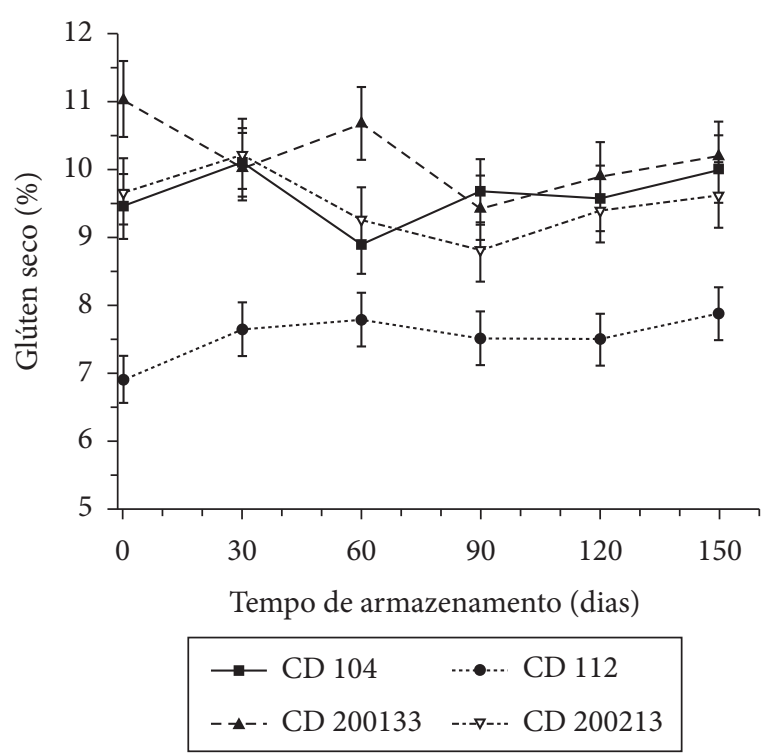

Figura 3. Glúten seco em função do tempo de armazenamento. 


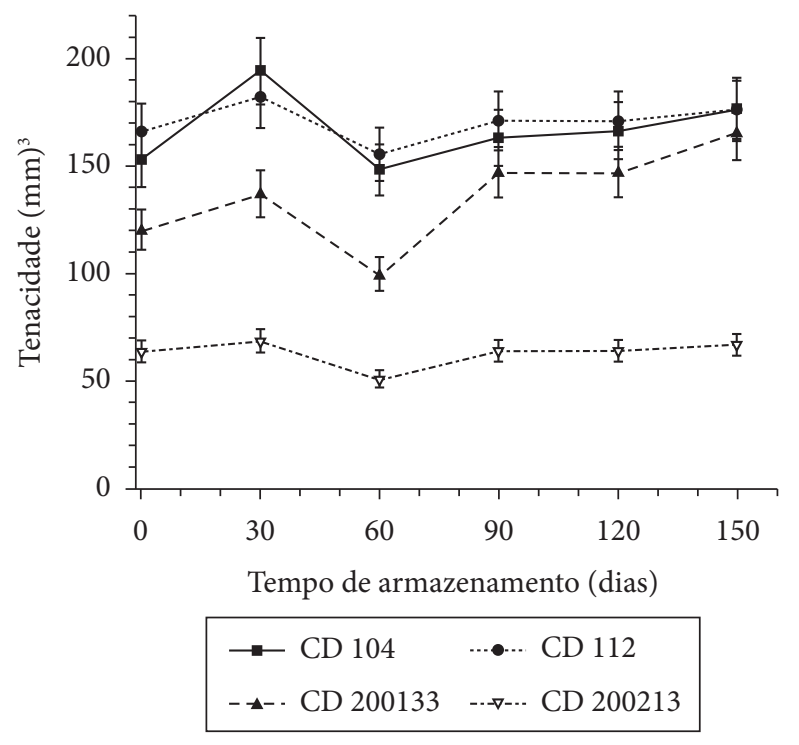

Figura 4. Tenacidade em função do tempo de armazenamento.

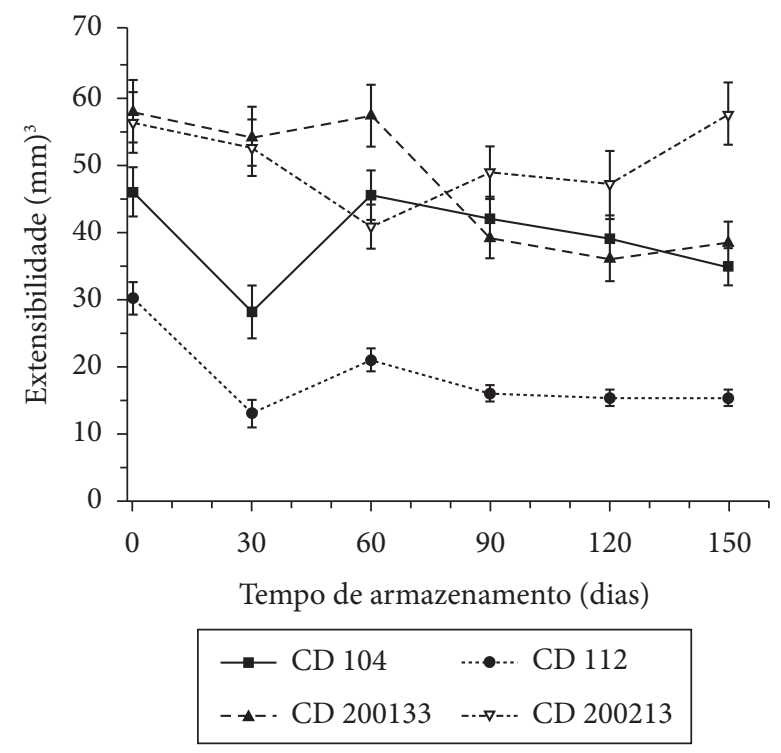

Figura 5. Extensibilidade em função do tempo de armazenamento.

que não houve nenhuma evolução significativa do número de queda com o tempo.

Resultados similares foram obtidos por Pirozi (1995) e Pirozi e Vilela (1998) que também observaram uma pequena redução na extensibilidade da massa. Quanto ao glúten, o trabalho de Pirozi (1995) apresentou diminuição na quantidade e na qualidade em 2 cultivares, enquanto que para o trigo melhorador não houve evolução. Já neste trabalho, observamos que não houve evolução da quantidade e nem da qualidade do glúten nos 4 cultivares analisados. Deve-se ressaltar que na época em que foi realizada a pesquisa de Pirozi (1995) não havia a Instrução Normativa ${ }^{\circ} 7$ (BRASIL, 2001) que firma a força do glúten e o número de queda como fatores únicos na

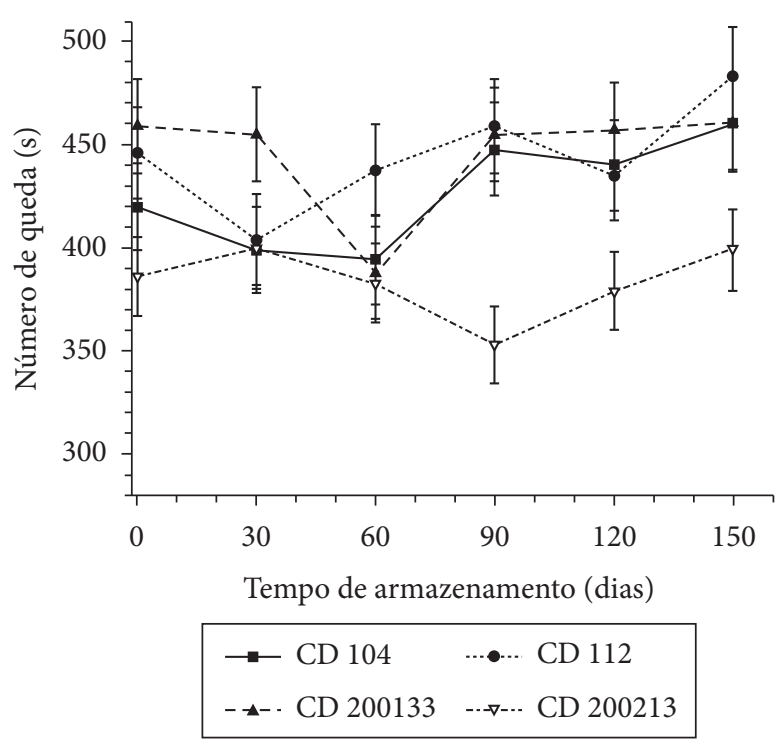

Figura 6. Número de queda (FN) em função do tempo de armazenamento.

classificação do trigo. Portanto, a comparação entre este trabalho e o apresentado por Pirozi (1995) fica prejudicada, pois na época não foram realizados testes com o número de queda.

\section{Conclusões}

Analisando os resultados obtidos verifica-se que, no período analisado, não ocorre evolução na força do glúten (W) e no número de queda (FN). As variações que ocorrem nas análises da tenacidade e da extensibilidade não são significativas do ponto de vista da indústria moageira. Assim, em relação às características reológicas, não existe a necessidade de retardar a aquisição e o uso do trigo na colheita. Desta forma, pode-se reduzir o custo de produção da farinha, pois, além da redução do custo com armazenamento, na época da colheita, normalmente, os preços tendem a baixar devido à maior disponibilidade de produto.

\section{Agradecimentos}

Aos técnicos da COODETEC, especialmente ao Dr. Francisco de Assis Franco pelo apoio durante todo o trabalho.

À Cotriguaçu por subsidiar parte dos custos financeiros e ceder o laboratório para as análises.

\section{Referências bibliográficas}

AMERICAN ASSOCIATION OF CEREAL CHEMISTS - AACC. Approved methods of the American Association of Cereal Chemists. 9 ed. Saint Paul, 1995.

Brasil. Ministério da Agricultura, do Abastecimento e da Reforma Agrária. Instrução normativa n.7, de 15 de agosto de 2001. Define as características de identidade e qualidade do trigo. Diário Oficial da República Federativa do Brasil, Brasília, 15 de Agosto de 2001. 
COSTA, M. G. et al. Qualidade tecnológica de grãos e farinhas de trigo nacionais e importados. Revista de Ciência e Tecnologia de Alimentos, v. 28, n. 1, p. 220-225, 2008.

GUTKOSKI, L. C.; NETO, R. J. Procedimento para Teste Laboratorial de Panificação - Pão tipo Forma. Ciência Rural, v. 32, n. 5, p. 873-879, 2002.

MANDARINO, J. M. G. Aspectos importantes para a qualidade do trigo. Londrina: Embrapa-CNPSo, 1993. 32 p. (Documento, 60).

PIROZI, M. R. Avaliação da qualidade tecnológica de variedades de trigo (Triticum aestivum) durante o armazenamento. Lavras, 1995, 149 p. Dissertação (Mestrado em Ciências dos Alimentos) Universidade Federal de Lavras - UFLA.
PIROZI, M. R.; VILELA, E. R. Alterações da qualidade tecnológica de grãos de trigo durante o armazenamento. Revista Ciência e Agrotecnologia, v. 22, n. 3, 1998.

RASPER, V. F. Quality evaluation of cereal and cereal products. In: LORENZ, K. J.; KULP, K. (Eds.). Handbook of cereal science and technology. New York: Marcel Dekker, 1991. p. 595-638.

Reunião da Comissão Centro Sul Brasileira de Pesquisa de Trigo, SEMINÁRIO TÉCNICO DO TRIGO, 19, 2004. Atlas, resumos e palestras... Londrina: CCSBPT, 2004.

ROSSI, R. M.; NEVES, M. F. Estratégias para o Trigo no Brasil. São Paulo: Atlas, 2004.

WIESIR, H. Chemistry of gluten proteins. Food Microbiology, v. 24, n. 2, p. 115-119, 2007. 